\title{
International Price Shocks Transmission: The Case of Rice in Togo
}

\author{
Tchalim Tom Irazou \\ Faculty of Economics and Management Science, University of Kara, P.O. Box 43, Kara, Togo
}

\begin{abstract}
The objective of the paper was to examine the relationship between the world rice price and the rice price in Togo using the linear and nonlinear co-integration tests. The author used the monthly prices for Togo local rice market and international market. The results show that the rice prices on the local market are integrated to international market. The elasticity of the long-term transmission is high. The threshold autoregression (TAR) model reveals an asymmetric transmission with a magnitude that varies depending on the nature of shock. Price increases in international markets are transmitted more rapidly to the local markets than price reductions. These results might be explained by the market power of traders, transport costs and government intervention.
\end{abstract}

Key words: Asymmetric transmission, price shocks, TAR model.

\section{Introduction}

The issue of integration of agricultural markets has long been debated in connection with the liberalization of food commodities markets in developing countries. It is a necessary condition for effective reform of agricultural markets. Indeed, agricultural markets' integration enables the exploitation of internal economies of scale, facilitates diffusion of innovations which are a source of externalities and increases the degree of competition, because it goes hand in hand with removing barriers and protecting markets [1]. In the absence of a spatial integration of markets, price signals are not transmitted in food surplus areas to food deficit areas, prices are instead more volatile, farmers are struggling to specialize according to the theory of comparative advantage and long-term trade gains are difficult to achieve.

The results of empirical studies on the degree of transmission of international price shocks to domestic prices are based on market characteristics. By using data from 22 developing countries over the period 1961 to 1987 , Hazell et al. [2] show that the change in world prices has not been passed to the prices paid to

Corresponding author: Tchalim Tom Irazou, Ph.D., research field: agricultural economics. producers. The authors explain this by the real exchange rate and mechanisms of policy makers' intervention. Furthermore, the authors found a strong correlation between producer prices and export prices for coffee, but not for others products. In their study based on a sample of 58 countries and price data for the period of 1968-1978, Mundlak and Larson [3] highlight a transmission almost perfect of variations in international prices to domestic prices in developing countries. Bakhshooddeh and Sahraeian [4] analyse agricultural market integration in Iran after its entry into the World Trade Organization, using price data for the period 1984 to 2002. The authors conclude that the national markets are not integrated into the long-term international markets and explain what result from government intervention mechanisms.

Price soaring of commodities on international markets during the period 2006-2008 renewed the debate on price transmission. This price surge began in 2002 and has greatly affected the food prices in 2006-2008. It led to the increased food insecurity and violent protests in large urban areas of many developing countries. The United Nations Food and Agriculture Organization (FAO) showed in a study of 2009 that food prices index increased 7\% in 2006 and 
$27 \%$ in 2007 [5]. This increase accelerated in the first half of 2008 to reach $61 \%$. Between January 2007 and March 2008, the prices of wheat and rice have almost doubled, while that of maize increased by $42 \%$.

In 2009, cereal prices have declined, but remained very high compared to their level at the beginning of 2006. For example, the average price of rice in 2009 was $90 \%$ higher compared to its average level in 2006. Several factors explain this food prices surge on international markets during 2006-2008.

Some studies have shown that the surge in food prices in the international markets during 2006-2008 resulted in a surge in food prices in many developing countries. This finding is not widespread as in some countries, and the rise in international prices has not been affected considerably. Various reasons are given to explain this situation. Among other factors, one can cite the poor quality of transport infrastructure and communication services, government's intervention mechanisms, complex chains of marketing, contractual arrangements between economic agents. Indeed, policies reforms in the agricultural sector can reduce the transmission of price changes from the international market to domestic markets, but also lead to an asymmetrical transmission increases and decreases in international prices.

The aim of this article was to estimate the transmission of international rice price shocks of imported rice on markets in Togo, while highlighting factors that may influence the degree of transmission. Togo is an importer of rice and nearly $65 \%$ of household consumption need are covered by imports. The main hypothesis is the existence of an asymmetry in price transmission due to high transport costs related to the quality of road infrastructure and the existence of government intervention mechanisms and market power of some commercial intermediaries.

\section{Review of the Empirical Literature}

Empirical studies on price transmission aim to provide information on how shocks occurring in one market are transmitted to another market, and highlight the degree of market integration and efficiency of their operation.

In past, many authors have studied price transmission at national or international level, for example, Ravallion [6], Sexton et al. [7], Dercon [8], Baulch [9] and Baffes and Gardner [10]. Recent studies are concerned with the asymmetric transmission of price, because some characteristics, such as government intervention, transportation costs, the quality of transport and communications infrastructure and commercial intermediaries' market power, can be source of asymmetries [11-17].

Many price forecasts predict an increase in agricultural prices in the short to medium term. By the year 2020, real prices are anticipated to be $20 \%$ higher for cereals and $50 \%$ higher for meats compared with previous decades [18].

\subsection{Traditional Approaches}

The question of how a price shock on a given market is transmitted to another market has long been debated in the literature on the agricultural economy. These studies differ according to econometric technique and the types of market considered.

Some studies focus on the relationship between the international market and domestic market; others focus on the relationship between deficit and surplus in markets of same country or region. All these studies have helped to clarify the issue, but it has not been completely resolved. In this section, the author presents the main methods, while highlighting their limitations.

The first studies on price transmission used an approach based on simple price correlations. Thus, a high correlation coefficient is synonymous of important price covariation and is interpreted as a factor of markets' performance. This approach has enormous weaknesses, especially when price data are non-stationary or in the case of an economic system where the stocks are important. 
Other approaches have been used to take into account the weaknesses related to simple correlation of prices. They are based on the estimation of static models or dynamic models, such as error correction models (ECM). For example, Mundlak and Larson [3] use a static regression model to estimate price transmission of international food goods prices to domestic prices in 58 countries using annual price data provided by FAO. The authors show a transmission almost perfect of prices. They find a middle transmission elasticity of 0.95 , which means that $95 \%$ of world price fluctuations are transmitted to domestic markets.

The static regression method assumes instant response of prices in a secondary market to price changes in the central market. However, there is generally a delay between the price change in a market and its impact on another market. These dynamic effects can be captured by introducing into the econometric relationship prices delayed as explanatory variables as seen in Ref. [6]. Furthermore, the assumption that the variables are stationary is not always true. When the series are non-stationary, the estimated coefficients are unbiased, but error distribution does not follow a normal distribution, so that the statistical significance tests used are invalid.

To remedy the problems associated with dynamic effects and non-stationary series, the ECM was used to analyse price [19]. Quiroz and Soto [20] use a dynamic econometric model to duplicate the study of Mundlak and Larson [3] with the same data. The authors conclude an absence of long-term relationship between domestic prices and international prices for 30 out of the 78 sample countries. In countries where there is a relationship, convergence is very low in many cases. Enders and Siklos [21] use ECM to analyse price transmission on a sample of 31 pairs of countries and products over the period 1970-1990. The authors conclude that only a small part of the world price variations are transmitted to domestic prices. Introducing structural breaks in their model, the authors show that the reforms contribute to significantly reduce the transmission of prices. Conforti [22] analyses the transmission of prices of a sample of 16 countries, including three Sub-Saharan African countries for seven types of agricultural products, using ECM. The results obtained for African countries differ by country and by type of product. In Ethiopia, the authors show a long-term relationship between world prices and domestic prices of wheat, sorghum and maize. In Ghana, there is a relationship between the international price and the domestic price for wheat, but no relationship for maize and sorghum. In Senegal, authors find a long-term relationship for rice but not for corn.

Despite the interest accorded to ECM to analyse the transmission of price, significant weaknesses were identified in these models [9, 23], which has implications for the analysis of the performance of markets. Generally, these models are based on two key assumptions. One is that trade margins and transaction costs are stationary. The second hypothesis assumes that trade is one-way. These assumptions are not always verified, especially in the context of developing countries which could give misleading results [23]. To overcome these difficulties, an econometric technique developed by Balke and Fomby [24] is used. This is the threshold autoregressive (TAR). This model allows to analyse the asymmetric price transmission.

\subsection{Asymmetric Price Transmission}

The hypothesis of asymmetric price transmission has been the subject of particular attention in the literature on agricultural markets, e.g., in Refs. [12, 24]. According to this hypothesis, in case of price shock causing a deflection of the balance exceeding a critical threshold, economic agents act to bring the system to equilibrium. The speed of their action depends on the nature of the shock. In agricultural economics, an asymmetry in the price transmission is due, for example, to imperfect competition, 
transportation costs, mechanisms of government intervention in the agricultural sector and commercial intermediaries.

Domestic markets can be isolated because of the very large margins related to transportation costs and marketing costs. In developing countries, inadequate transport infrastructure and communication services give rise to strong commercial margins due to high costs to transport of commodities. High transaction costs and strong marketing margins hinder the transmission of price signals, and insofar they may prohibit arbitrage [7].

One factor regularly cited in the empirical literature as a source of asymmetry in the transmission of agricultural prices is the market power of intermediaries business. An economic environment characterized by oligopolistic behaviours and agreements between traders at national level may continue to higher levels than those determined by transport costs of the price differences between national and international awards. The concentration in marketing and in the food processing and non-competitive behaviour beyond agricultural operations can enable market intermediaries to have pricing power. Stocks also play an important role in the asymmetric price transmission. If the agents expect a rise in price for a particular property in the next period, they will tend to increase their stocks, which will have the effect of increasing the price of good over domestic market. But if expectations are in line with a downward trend prices in the next period, the agents will reduce the amount of stocks by supplying markets, and this will have the effect of lowering the price level. Such a situation will prevent a total transmission of price changes on the international market to local markets.

The application of price support policies in the agricultural sector may lead the international price and the domestic price to disconnect or to be connected non-linearly, depending on the level of intervention compared to international prices. The international price changes will have no effect on the domestic price, if the international price is fixed below the level at which the minimum price was set. Thus, policies based on a minimum price may bring the domestic price to be totally detached from international price below a certain level determined by the floor price.

Krivonos [25] analyses the impact of reforms in the coffee sector during the $80 \mathrm{~s}$ and $90 \mathrm{~s}$ on coffee producers and asymmetric price transmission in development countries using dynamic model used by Baffes and Gardner [10]. The author shows that in some cases, the impact of the transmission reforms is asymmetric, that is, the price increases are transmitted more rapidly than decreases.

Araujo et al. [15] test the impact of the recent oil shock on millet market' performance in Niger from a panel sample of 66 pairs of markets in the period from January 1990 to October 2008 based on a threshold model. The authors show that price imbalances take longer to be reabsorbed when the oil price is high, but the difference remains stationary.

Abdulai [12] analyses the price transmission on the main corn markets in Ghana using a TAR model. Maize marketing in Ghana is organized through networks of traders that maintain ethnic and personalized relationships. The retailers and small businesses dominate the local and regional markets, while wholesalers make spatial arbitrage to take advantage of the best prices. The author shows that commercial intermediaries significantly influence the transmission of price shocks from the central market and the wholesale selling prices on the secondary market adjusts faster than the increases in the central market declines.

\subsection{Chain of Imported Rice in Togo}

Rice is ranked the third in the household food consumption after corn and sorghum. It occupies an important place in the economy of the country, because large outflows of foreign currency are related to massive imports each year to satisfy a growing 
demand that domestic production can not cover. The rice is produced on the entire country, but varies across regions. The major production area is the Plateaux region.

Rice imports have increased rapidly from 12,000 tons in 1991 to 104,000 tons in 2006. Domestic rice consumption, partly due to population diet change, increases at the rate of $6 \%$ per year, a much higher rate than domestic production (at best $2 \%$ per year). The production of the country covers at a time today only $50 \%$ of national consumption. Current consumption of rice in Togo (about $17 \mathrm{~kg} /$ capita per year) is still low compared to the average sub-regional and would ever have increasing demand. Imported rice comes from several countries, including those in Europe, Asia and America, but Asia remains the continent which exports more rice to Togo $(80 \%$ of imports).

The value chain analysis of imported rice in the market of Togo suggests the existence of an oligopolistic system maintained by a number of intermediaries. This justifies the author's working hypothesis, which assumes the existence of an asymmetry in the transmission of international price shocks to prices on the markets of Togo. Under this assumption, commercial intermediaries will tend to reverberate increases of the international price of rice in the domestic price faster than they do in the case of price decline.

\section{Econometric Estimation Strategy}

The estimation strategy used is based on the application of co-integration methods. The author first determines the statistical properties of the price series sample using the unit root tests. Then conduct standards of co-integration tests. Finally, carry out tests based on the TAR model for the presence of asymmetry in price transmission.

\subsection{Standard Tests of Stationarity and Co-integration}

There are a large number of unit root tests to test the non-stationarity of series. Augmented Dickey-Fuller (ADF), Phillips-Perron (PP) and Kwiatkowski-Phillips-Schmidt-Shin (KPSS) tests are applied for this analysis. The author then tests the hypothesis of no co-integration price series using the methods described in Refs. [26, 27]. To test the hypothesis of non-co-integration of series from the method of Engle-Granger, the author starts from the long-run equilibrium relationship between international prices of rice and the price of imported rice in Togo, as Eq. (1):

$$
P_{t}=\alpha_{0}+\alpha_{1} P_{t}^{m}+\gamma_{t}
$$

where, $P_{t}$ and $P_{t}^{m}$ are the domestic rice price and the world rice price, respectively, both expressed in CFA franc. $\gamma_{t}$ is the random error term with constant variance, which can be correlated. The random term captures the effect of unobservable variables, such as cost of transaction, intervention policies. If $\gamma_{t}$ is stationary, the two price series are cointegrated, implying they have a long-term stable relationship. The coefficient $\alpha_{1}$ represents the elasticity of the transmission of the long term. It measures the proportion of $P_{t}^{m}$ variations transmitted to $P_{t} . \alpha_{0}$ is a constant term. In the absence of international price shock transmission, the domestic price $P_{t}$ is equal to $\alpha_{0}$.

Several factors influence the degree of transmission of world price fluctuations on domestic markets, that is the case, for example, of trade policies at the border. An import ad valorem tax is compatible with a total transmission of price shocks, which corresponds to a transmission of elasticity equal to unity. By contrast, an import quota policy or a tax on import may reduce the fixed transmission elasticity in the long term.

The Engle-Granger method to test the null hypothesis of non-co-integration applies the residue of Eq. (1), as defined in Eq. (2):

$$
\Delta \gamma_{t}=\rho \gamma_{t-1}+\varepsilon_{t}
$$

where, $\varepsilon_{t}$ is an independent and identical distributed error term. 
The standard co-integration tests, namely the ADF test, PP test and KPSS test are performed in Eq. (2). The hypothesis of non-co-integration can be rejected, if the residuals are stationary and zero mean. The author also realizes the Johansen co-integration test. If the tests disprove the hypothesis of non-co-integration, the ECM is to be estimated to examine the short-term dynamics. This model is defined as Eq. (3):

$$
\begin{gathered}
\Delta P_{t}=\gamma \gamma_{t-1}+\sum_{k=1}^{p} \theta_{k} \Delta P_{t-k}^{m}+ \\
\sum_{k=1}^{p} \rho_{k} \Delta P_{t-k}+\mu_{t}
\end{gathered}
$$

where, $\gamma$ is the speed of adjustment of $P_{t}$ and $\theta_{k}$ accounts for short-term elasticities transmission (short-term dynamics).

\subsection{Asymmetric Transmission Model}

The assumption that the price increases on the international market are transmitted more quickly to national markets than international price decline is tested using TAR model, as Eq. (4):

$$
\Delta \gamma_{t}=I_{t} \sigma_{1} \gamma_{t-1}+\left(1-I_{t}\right) \sigma_{2} \gamma_{t-1}+\Psi_{t}
$$

where, $\gamma_{t}$ is the error term of Eq. (1) and $I$ is an indicator function defined as Eq. (5):

$$
I_{t}= \begin{cases}1 & \text { if } \gamma_{t-1} \geq 0 \\ 0 & \text { if } \gamma_{t-1}<0\end{cases}
$$

where, the long-term equilibrium is given by $\gamma_{t-1}=0$. If $\gamma_{t-1}>0$, this means that a decrease in the international price causes a positive deviation from the long-term equilibrium, in this case, the adjustment is equal to $\sigma_{1} \gamma_{t-1}$. If $\gamma_{t-1}<0$, a rise in the international price results a negative deviation from the equilibrium, in this case, the adjustment is equal to $\sigma_{2} \gamma_{t-1}$. Moreover, if $\sigma_{1}$ is less than $\sigma_{2}$, then the positive deviations are more rapidly resorbed than the negative deviations.

It is possible that the threshold is not zero, the relation in Eq. (5) becomes as Eq. (6):

$$
I_{t}= \begin{cases}1 & \text { if } \gamma_{t-1} \geq \tau \\ 0 & \text { if } \gamma_{t-1}<\tau\end{cases}
$$

where, $\tau$ is the threshold value, which is estimated endogenously. To reflect the dynamic adjustment effects, Engle and Granger [19] show that Eq. (4) can be modified by adding delays of $\gamma_{t}$. Indeed, Eq. (4) does enough to capture the dynamic adjustment to its long-term equilibrium value. Then, Eq. (4) is modified as Eq. (7):

$$
\begin{aligned}
\Delta \gamma_{t}= & I_{t} \rho_{t} \gamma_{t-1}+\left(1-I_{t}\right) \rho_{2} \gamma_{t-1} \\
& +\sum_{i=1}^{p-1} \gamma_{i} \Delta \gamma_{t-1}+\varepsilon_{t}
\end{aligned}
$$

Before estimating Eq. (7), we need to ensure the absence of residues and autocorrelation by selecting the appropriate number of delays. The autocorrelation of the residuals is tested using the Ljung-Box tests and the number of delays is determined from the Akaike information criterion (AIC).

The co-integration test in the TAR model is based on the coefficients $\sigma_{1}$ and $\rho_{2}$. If the hypothesis of prices co-integration is verified, the coefficients are negative. Enders and Siklos [21] using two tests-the $t$-max (the larger of the two statistics) and $t$-min (the smallest) to test the hypothesis that the coefficients are significantly negative and an $F$-test to test the hypothesis that they are jointly different from zero. The critical values of these tests are given in Ref. [21]. To estimate the threshold value in Eq. (6), the author uses the method described in Ref. [28]. The author has shown that it is possible to obtain a good threshold estimator from minimizing the sum of squared residuals. The procedure involves residuals estimation of Eq. (1), which are then sorted in ascending order, $15 \%$ the highest values and $15 \%$ of the lowest values are discarded and $70 \%$ remaining values are considered potential thresholds. Eq. (7) is estimated for each of the potential levels. The estimated value of the threshold from the minimization of the residual sum of squares is used.

Eqs. (1), (4) and (6) allow to estimating an error correction model, which is specified as Eq. (8):

$$
\Delta P_{t}=\lambda_{1} I_{1} \gamma_{t-1}+\lambda_{2}\left(1-I_{t}\right) \gamma_{t-1}+
$$




$$
\sum_{k=1}^{P} \alpha_{k} \Delta P_{t-k}^{m}+\sum_{k=1}^{P} \beta_{k} \Delta P_{t-k}+\eta_{t}
$$

where, $\lambda_{1}$ and $\lambda_{2}$ are adjustment coefficients for positive chocks (price decreases) and negative shocks (price increases), respectively.

\section{Econometric Results}

\subsection{Descriptive Statistics of the Data}

The average price of rice over the period 1991-2013 on the local market is equal to $282 \mathrm{CFA}$. This average price represents almost double of the average price on the international market (Table 1). The coefficient of variation is equal to 0.33 for the international market and 0.21 for the local markets. The coefficient of variation is lower for the interior prices compared to international prices. This is mostly explained by the high transaction costs between the international market and the national markets. The correlation coefficient is 0.87. This highlights the existence of positive relationships between international and local markets.

\subsection{Data and Stationarity Test}

The analysis uses monthly price data from the local rice market and the international price from January 1991 to December 2013. The price data for the two markets come from FAO database [29]. To estimate the relationship between rice prices in the market in Togo and the international rice price, the work has been divided into two components. First, the standard unit root test, co-integration test and Granger causality tests are applied. Then, to test the hypothesis of asymmetric transmission, the TAR model is estimated. Estimation results indicate that domestic rice price and international rice price are co-integrated with high transmission elasticity. The TAR model reveals the presence of asymmetry in the transmission of price shocks.

The results of ADF, PP and KPSS test are presented in Table 2. They show that the price series are integrated with order.

\subsection{Co-integration Tests of Price Series}

The estimation of the long-term relationship in Eq. (1) provides a transmission elasticity of 0.799 (Table 3). The co-integration test is then applied to the residues of the long-term relationship [19]. The number of delays in the test equation is determined by AIC. The test results reflect the rejection of the non-co-integration hypothesis for both markets. This means that domestic prices are co-integrated with international prices.

The Johansen co-integration test confirms the existence of a linear co-integration relationship between international rice price and local rice price.

Table 1 Descriptive statistics of the data.

\begin{tabular}{lllllll}
\hline Variables & Obs & Mean & SD & CV & Min. & Max. \\
\hline International price & 276 & 189.45 & 57.80 & 0.33 & 107.00 & 420.45 \\
Domestic price & 276 & 251.70 & 65.90 & 0.45 & 152.00 & 374.76 \\
\hline
\end{tabular}

Source: author's estimation from FAOSTA, 2013. Obs: observations; SD: standard deviation; CV: coefficient of variation.

Table 2 Unit root test on the monthly data from 1991 to 2013.

\begin{tabular}{llllll}
\hline Variables & ADF & Probability & PP & Probality & KPSS \\
\hline Local price & -0.190 & 0.640 & -0.543 & 0.467 & $0.368^{*}$ \\
Local price in first difference & $18.796^{* * *}$ & 0.000 & $-18.900^{* * *}$ & 0.000 & 0.146 \\
International price in level & -0.450 & 0.518 & -0.485 & 0.502 & $0.423^{*}$ \\
International price in first difference & $-9.764^{* * *}$ & 0.000 & $-8.560^{* * *}$ & 0.000 & 0.410 \\
\hline
\end{tabular}

Source: author's estimation from FAOSTA, 2013. ${ }^{* * *}$ Significant at $1 \%$ and $*$ significant at $10 \%$. 
Table 3 Long-term relationship between international price and local price.

\begin{tabular}{ll}
\hline Variables & Coefficients \\
\hline Constant & $0.436^{* * *}$ \\
& $(0.039)$ \\
International price & $0.799^{* * *}$ \\
Obs & $(0.050)$ \\
\hline
\end{tabular}

Source: author's estimation from FAOSTA, 2013. *** Significant at $1 \%$.

Table 4 Error correction model.

\begin{tabular}{ll}
\hline Variables & Coefficients \\
\hline Constant & $0.108^{* *}$ \\
& $(0.040)$ \\
Adjustment speed & $-0.069^{* * *}$ \\
& $(0.015)$ \\
International price lagged & $0.259^{* * *}$ \\
& $(0.036)$ \\
Obs & 276 \\
\hline
\end{tabular}

Source: author's estimation from FAOSTA, 2013. *** Significant at $1 \%$ threshold and $* *$ significant at $5 \%$.

Table 4 presents the results of the estimate of the standard error correction model for the short-term dynamics over the period 1991-2013. Short-term transmission elasticity appears relatively low $(0.26)$.

\subsection{Asymmetric Co-integration Tests}

The results of asymmetric co-integration test with a delay and a threshold equal to zero (Table 5) show that the coefficients $\sigma_{1}$ and $\rho_{2}$ are significantly different from zero ( $t$-max and $F$-test). The value of the $F$-test is of 12.345 for the relationship between the local market and the international market. This value appears higher than the value in critical ${ }^{1}$ threshold at $5 \%$ (5.87). This result allows to reject the null hypothesis of no co-integration. Then the hypothesis of symmetric adjustment is tested. This hypothesis assumes equal coefficients $\left(\sigma_{1}=\rho_{2}\right)$ and is tested from the standard Fisher test or Wald test. The test results give value of 5.341 about the domestic market and the international market relationship. The hypothesis of symmetrical adjustment of prices is

\footnotetext{
1 The critical values are those of Enders and Siklos (2001). These are defined by the joint $F$ statistic test proposed by the two authors.
}

therefore rejected for a zero threshold.

The estimated coefficients of $\sigma_{1}$ and $\rho_{2}$ are -0.223 and -0.456 , respectively. This indicates that approximately $22 \%$ of positive deviations from the long-term equilibrium are resorbed during a month. By contrast, $46 \%$ of the negative deviations with respect to the balance are resorbed during a month. These results indicate that shocks to the origin of the positive deviations are more persistent than those originally from negative deviations.

Analysis of the short-term dynamics from the asymmetric error correction model shows that a $1 \%$ increase in the international price leads to an increase of about $0.11 \%$ of the domestic market price (Table 6). Furthermore, domestic market prices significantly respond to positive and negative deviations from equilibrium.

In the previous estimates, a zero threshold was considered. In this part, a threshold was endogenously

Table 5 TAR model on long-term residuals for a null threshold.

\begin{tabular}{ll}
\hline Parameters & Values \\
\hline$\sigma_{1}$ & $-0.223^{* * *}$ \\
& $(0.029)$ \\
$\rho_{2}$ & $-0.456^{* * *}$ \\
Obs & $(0.010)$ \\
t-max & 276 \\
$\mathrm{~F}\left(\sigma_{1}=\rho_{2}=0\right)$ & $-6.323^{* * *}$ \\
Wald $\left(\sigma_{1}=\rho_{2}\right)$ & $12.345^{* * *}$ \\
Source: author's estimation from FAOSTA, 2013. *** Significant \\
at $1 \%$ threshold.
\end{tabular}

Table 6 TAR model on long-term residuals for a null threshold.

\begin{tabular}{ll}
\hline Parameters & Values \\
\hline$\lambda_{1}$ & $-0.123^{* * *}$ \\
& $(0.029)$ \\
$\lambda_{2}$ & $-0.356^{* * *}$ \\
International price variation & $(0.023)$ \\
lagged & $-0.117^{* * *}$ \\
Constant & $(0.009)$ \\
Wald & $0.100^{* *}$ \\
Obs & $(0.033)$ \\
\hline
\end{tabular}

Source: author's estimation from FAOSTA, 2013. *** Significant at $1 \%$ threshold and $* *$ significant at $5 \%$. 
Table 7 TAR model with endogenous threshold.

\begin{tabular}{ll}
\hline Parameters & Values \\
\hline$\tau$ & -0.122 \\
$\sigma_{1}$ & $-0.304^{* * *}$ \\
& $(0.029)$ \\
$\rho_{2}$ & $-0.556^{* * *}$ \\
$\mathrm{t}-\mathrm{max}$ & $(0.053)$ \\
$\mathrm{F}\left(\sigma_{1}=\rho_{2}=0\right)$ & $-4.323^{* * *}$ \\
Wald $\left(\sigma_{1}=\rho_{2}\right)$ & $11.345^{* * *}$ \\
\hline Source: author's estimation from FAOSTA, 2013. ${ }^{* * *}$ Significant \\
at $1 \%$ threshold.
\end{tabular}

Table 8 Asymmetric error correction model with endogenous threshold.

\begin{tabular}{ll}
\hline Parameters & Values \\
\hline$\lambda_{1}$ & $-0.223^{* * *}$ \\
& $(0.044)$ \\
\hline$\lambda_{2}$ & $-0.48^{* * *}$ \\
International price variation & $(0.021)$ \\
lagged & $-0.106^{* * *}$ \\
Constant & $(0.012)$ \\
Wald & $0.102^{* *}$ \\
Obs & $(0.027)$ \\
Sourc: athor's estmation & $5.991^{* * *}$ \\
\hline
\end{tabular}

Source: author's estimation from FAOSTA, 2013. *** Significant at $1 \% \mathrm{t}$ and $* *$ significant at $5 \%$.

determined. The technique used to estimate thresholds by Chan [28] gives $\tau$ values $=-0.122$. The results in Table 7 show that coefficients $\sigma_{1}$ and $\rho_{2}$ are significantly different from zero and are jointly different from zero (based on $t$-Max and $F$-test). Analysis of the short-term dynamics from the error correction model with endogenous threshold shows that a $1 \%$ increase in the international price leads to an increase of approximately $10 \%$ of the domestic market prices (Table 8). Indeed, local market prices respond significantly to positive and negative deviations from equilibrium. Thus, the estimated values of $\lambda_{1}=-0.223$ and $\lambda_{2}=-0.48$ indicate that the adjustment of domestic prices allows to eliminate $22.3 \%$ of a negative deviation from the threshold and $48 \%$ of a positive deviation. This means that there is asymmetric co-integration between rice prices in domestic markets and international prices for different thresholds scratch. Increases in international rice prices are transmitted more quickly than decreases. The hypothesis of symmetric adjustment of prices is also rejected.

\section{Conclusions}

The analysis applied to Togo is particularly interested in the asymmetrical transmission. It provides insight from methodological point of view to analysis of price transmission. The main hypothesis tested is the existence of asymmetry in price transmission. According to this hypothesis, the prices on national markets respond more quickly to increases of international prices than decreases. Indeed, commercial intermediates, forming a oligopolistic system, is trying to pass faster international price increases to domestic prices, which is causing a mismatch in speed adjustment of domestic prices compared to international prices.

Overall, the results show that prices on the domestic rice market in Togo respond to changes in price of rice on the international market. This finding is revealing a lack of performance in the functioning of markets in Togo. The asymmetry in the transmission of international price shocks to domestic prices tends to confirm the existence of an intermediate market power, which prevents a better transmission of price. One of the measures for efficient markets would be to implement policies preventing high concentration of import rice activities with the aim of allowing high trade competition of imported rice in domestic markets. This would help limit the market power of market intermediaries and consequently improve functioning of markets.

\section{References}

[1] Araujo-Bonjean, C., and Combes, J. L. 2010. "Measurement of the Integration of Agricultural Markets in Developing Countries." Review of Development Economics 107 (46): 5-20. (in French)

[2] Hazell, P. B. R., Jaramillo, M., and Williamson, A. 1990. "The Relationship between World Price Instability and the Prices Farmers Receive in Developing Countries." Journal of Agricultural Economics 41 (2): 227-41.

[3] Mundlak, Y., and Larson, D. F. 1992. "On the Transmission of World Agricultural Prices.” World Bank Economic Review 6 (3): 399-422. 
[4] Bakhshooddeh, M., and Sahraeian, M. 2006. "Agricultural Market Integrations and Accession to WTO: An Application to the Major Crops in Iran.” Presented at the International Conference on WTO and Its Impact on Developing Countries with Special Reference to Agriculture and Education, Abasaheb Garware College Campus Pune, India, February 14-16, 2007.

[5] Food and Agriculture Organization of the United Nations (FAO). 2009. "The State of Food Insecurity in the World: Economic Crises-Impacts and Lessons Learned.” FAO Report, Rome. Accessed July 2014. http://www.fao.org/docrep/012/i0876e/i0876e00.htm.

[6] Ravallion, M. 1986. "Testing Market Integration." American Journal of Agricultural Economics 68 (1): 102-9.

[7] Sexton, R., Kling, C., and Carman, H. 1991. "Market Integration, Efficiency of Arbitrage and Imperfect Competition: Methodology and Application to U.S. Celery." American Journal of Agricultural Economics 73 (3): 568-80.

[8] Dercon, S. 1995. "On Market Integration and Liberalization: Method and Application to Ethiopia." Journal of Development Studies 32 (1): 112-43.

[9] Baulch, B. 1997. "Transfer Costs, Spatial Arbitrage and Testing for Food Market Integration.” American Journal of Agricultural Economics 79 (2): 477-87.

[10] Baffes, J., and Gardner, B. L. 2003. "The Transmission of World Commodity Prices to Domestic Markets under Policy Reforms in Developing Countries." Journal of Policy Reform 6 (3): 159-80.

[11] Roberts, J. M., Stockton, D. J., and Struckmeyer, C. S. 1994. "Evidence on the Flexibility of Prices." Review of Economics and Statistics 76 (1): 142-50.

[12] Abdulai, A. 2000. "Spatial Price Transmission and Asymmetry in the Ghanaian Maize Market." Journal of Development Economics 63 (2): 327-49.

[13] Meyer, J., and Von Cramon-Taubadel, S. 2004. "Asymmetric Price Transmission: A Survey." Journal of Agricultural Economics 55 (3): 581-611.

[14] Araujo, C., Araujo-Bonjean, C., Combes, J. L., and Motel-Combes, P. 2005. "Devaluation and Cattle Market Integration in Burkina Faso." Journal of African Economies 14 (3): 359-84.

[15] Araujo, C., Araujo-Bonjean, C., and Egg, J. 2010. "External Oil Crisis and the Performance of Cereals" Market: The Market of Millet in Niger." Review of the Development Economics 1: 47-70. (in French)
[16] Badolo, F. 2012. "Transmission of the Shocks of International Prices: The Case of Rice in Burkina Faso." Economic News, September 3. (in French)

[17] Subervie, J. 2008. Rupture and Asymmetry in the Transmission of the World Agricultural Prices. CERDI Studies and Documents No. 22, Clermont-Ferrand.

[18] Organization for Economic Cooperation and Development and Food and Agriculture Organization of the United Nations (OECD-FAO). 2011. Agricultural Outlook.

[19] Engle, R. F., and Granger, C. W. J. 1987. "Co-integration and Error Correction: Representation, Estimation and Testing." Econometrica 55 (2): 251-76.

[20] Quiroz, J., and Soto, R. 1995. "International Price Signals in Agricultural Prices: Do Governments Care?" Ph.D. thesis, ILADES Documento de Investigacion No. 88, Georgetown University, Santiago.

[21] Enders, W., and Siklos, P. L. 2001. "Co-integration and Threshold Adjustment." Journal of Business and Economic Statistics 19 (2): 166-76.

[22] Conforti, P. 2004. "Price Transmission in Selected Agricultural Markets." FAO Commodity and Trade Policy Research Working Paper No. 7, Rome.

[23] Barrett, C. B. 1996. "Market Analysis Methods: Are Our Enriched Toolkits Well-Suited to Enlivened Markets?" American Journal of Agricultural Economics 78 (3): 825-9.

[24] Balke, N. S., and Fomby, T. B. 1997. "Threshold Co-integration." International Economic Review 38 (3): 627-45.

[25] Krivonos, E. 2004. "The Impact of Coffee Market Reforms on Producer Prices and Price Transmission." World Bank Working Paper No. 3358, Washington, D.C.

[26] Enders, W., and Granger, C. W. J. 1998. "Unit Root Tests and Asymmetric Adjustment with an Example Using the Term Structure of Interest Rates." Journal of Business and Economic Statistics 16 (3): 304-11.

[27] Johansen, S. 1988. "Statistical Analysis of Cointégration Vectors." Journal of Economic Dynamics and Control 12: 231-54.

[28] Chan, K. S. 1993. "Consistency and Limiting Distribution of the Least Squares Estimation of a Threshold Autoregressive Model." The Annals Statistics 21 (1): 520-33.

[29] Food and Agriculture Organization of the United Nations (FAO). 2013. "The FAOSTAT Database.” Accessed July 2014. http://faostat.fao.org/site/609/default.aspx\#ancor. 